\title{
Prevalence of impacted premolar in Iraqi sample
}

\author{
Zainab H. Al-Ghurabi, B.D.S., M.Sc. \\ Assistant Lecture, Department of Oral Diagnosis, College of Dentistry, University of Baghdad, Baghdad, Iraq.
}

\begin{abstract}
:
Background: The most commonly impacted teeth are the third molars, maxillary canines, maxillary central incisors and premolars. Impacted premolars may lead to aesthetic concerns, masticatory inefficiency and oral hygiene difficulties as well as follicle pathology and destruction of adjacent structures, including neighboring teeth, the purpose of this study to shade light on the prevalence of impacted premolar in Iraqi sample.
\end{abstract}

Subject, materials and method: Retrospective and protrospective studies invoved 2000 OPG examined by radiologist for age ranged between 15-55 years to indicate the prevelance of impacted premolar, uni or bilateral impaction, migration of impacted premolar and its association with pathology.

Result: From 2000 OPG 99 patient with( 101 impacted premolar), 2 (204.\%) bilateral and 97 (97.97\%) unilateral, prevelance of upper 1 st and 2 nd premolar was (2.97\%) and (5.94\%) respectively, while for lower 1 st and 2nd premolar was (11.88\%) and (79.20\%) respectively. From all impacted premolars only (2.97\%) associated with pathology and (0.99\%) migrated teeth.

Conclusion: The most prominent one of premolars was lower 2 nd premolar and the latest one waslst upper premolar, migrated teeth was very rare and the pathology associated with $(2.97 \%)$ only. The causes related with impaction in this study retaind first decediouce molar and not enough space for eruption

Key words: Impaction, OPG, premolars.

\section{Introduction}

An impacted tooth is one that is embedded in the alveolus so that its eruption is prevented or the tooth is locked in position by bone or the adjacent teeth. Lack of space due to the crowding of the dental arches or due to premature loss of primary teeth with subsequent partial closure of their area which is a common factor in the etiology of partially or completely impacted teeth. Genetic and environmental factors are included in the multifactorial nature of tooth eruption, which may be disturbed at any stage of tooth development ${ }^{(1)}$.

Mandibular second premolars rank third after third permanent molars and maxillary permanent canines in frequency of impaction. The prevalence of impacted premolars has been found to vary according to age. The overall prevalence in adults has been reported to be $0.5 \%$ the range being 0.2 to $0.3 \%$ for mandibular premolars ${ }^{(2,3)}$ and $0.1 \%$ to $0.3 \%$ for maxillary premolar ${ }^{(3,4)}$.

Impaction of the mandibular $2^{\text {nd }}$ premolar has also been related to the initial angulation of the tooth and the early loss of the first permanent molar ${ }^{(5)}$.The other causes leading to this problem include, over-retained or infraocclusal and ankylosed primary molars ${ }^{(6)}$ ectopic positioning of the developing premolar tooth buds; or pathology such as inflammatory or dentigerous cysts, extrinsic obstructions, such as supernumerary teeth and odontomas, they may also be associated with thick and fibrous gingival tissue ${ }^{(7,8,9)}$.

Impaction of second mandibular premolar may lead to several problems in occlusion such as loss of space due to mesial drift of molar and distal movement of mandibular first premolar.

Impacted premolars may lead to aesthetic concerns, masticatory inefficiency and oral hygiene difficulties ${ }^{(2)}$ as well as follicle pathology and destruction of adjacent structures, including neighboring teeth $(2,10)$

Literature specific to impacted premolars is not extensive, despite the fact that mandibular second premolars alone account for approximately $24 \%$ of all dental impactions ${ }^{(11),}$,therefore, when any permanent tooth is clinically missing, a panoramic radiographic examination is essential The aim of this study was to clear the prevalence of impacted premolar in Iraqi sample depending on radiographic assessment (OPG).

\section{Materials And Methods}

This retrospective \& protrospective studies examined panoramic radiographs of 2,000 patient over the age of $15 y e a r s ~ t o ~ 55$ years, who presented consecutively at oral and maxillofacial radiology clinics in AL-Karkh 
general hospital, Specialest center of dentistry in Al-sadder cityand and collage of dentistry- university of Baghdad, in a period between January 2012 to October 2013, the No. of protrocpective were 500 patient examined clinically in addition to OPG while retrospective group only OPG were examined. Kodak 8000 and plameca OPG devices were used in our study. A tooth was considered to be impacted if it was not erupt with occlussal plane in a patient over 15 years of age. Data was collected on the number of the patient according side involvement (Uni or bilateral) and ratio of maxillary to mandibular impacted premolars, Impacted premolars were distributed based on whether or not they had undergone intra-osseous migration, which was defined as the movement of a tooth to an area far from its regular place of development, and according pathological assessment.

\section{Result}

Table 1: No. of patient according side involvement of impacted teeth

\begin{tabular}{|c|c|c|c|c|c|c|}
\hline & \multicolumn{2}{|c|}{ BILATERAL } & \multicolumn{2}{|c|}{ UNILATERAL } & \multirow[b]{2}{*}{ Patient } & \multirow[b]{2}{*}{ Bix Uni 4} \\
\hline & $\begin{array}{l}\text { Patient ( }\left(^{\text {st }}\right. \\
\text { premolar) }\end{array}$ & $\begin{array}{l}\text { Patient }\left(2^{\text {nd }}\right. \\
\text { premolar })\end{array}$ & $1^{\text {st }}$ premolar & $2^{\text {nd }}$ premolar & & \\
\hline Upper & $1(1.04 \%)$ & $0(0 \%)$ & $1(1.01 \%)$ & $6(6.06 \%)$ & $8(8.33 \%)$ & 4 \\
\hline Lower & $0(0 \%)$ & $1(1,01 \%)$ & $12(12.12 \%)$ & $78(78.78 \%)$ & $91(91.91 \%)$ & $\mathrm{X} 2=6.46 \mathrm{P}=0.011(\mathrm{~S})$ \\
\hline \multirow[t]{2}{*}{ Total } & $1(1.01 \%)$ & $1(1.01 \%)$ & $13(13.13 \%)$ & $84(84.84 \%)$ & $99(101)(100 \%)$ & 5 \\
\hline & \multicolumn{2}{|c|}{$2(2.04 \%)$} & \multicolumn{2}{|c|}{$97(97.97 \%)$} & & $\mathrm{X} 2=0.08 \mathrm{P}=0.78(\mathrm{NS})$ \\
\hline $4 \times 5$ & \multicolumn{2}{|c|}{$\mathrm{X} 2=2, \mathrm{p}=0.16(\mathrm{NS})$} & \multicolumn{2}{|c|}{$\mathrm{X} 2=0.005, \mathrm{p}=0.94(\mathrm{NS}$} & & \\
\hline
\end{tabular}

As shown in table 1, the rate of patient with unilateral impacted premolar was higher than those with bilateral, as clear the bilateral impacted premolars were seen in upper $1^{\text {st }}$ premolar and lower $2^{\text {nd }}$ premolar in 2 patients only

Table 2: Distturbution of I.p according Jaw and type of tooth

\begin{tabular}{|l|l|l|l|l|}
\hline & $\mathbf{1}^{\text {st }} \mathbf{p . m}$ & $\mathbf{2}^{\text {nd }} \mathbf{p . m}$ & total & \\
\hline Upper & $3(2.97 \%)$ & $6(5.94 \%)$ & $9(8.91 \%)$ & \multirow{2}{*}{$\mathrm{X} 2=2.67$} \\
\hline Lower & $12(11.88 \%)$ & $80(79.20 \%)$ & $92(91.08 \%)$ & \\
\hline Total & $15(14.85 \%)$ & $86(85.14 \%)$ & $101(100 \%)$ & $\mathrm{P}=0.1(\mathrm{NS})$ \\
\hline
\end{tabular}

Table 2 clear the differences of impaction percentage for each jaw and side, so the highest percentage of impacted premolar was in lower second premolar and the lowest percent in upper $1^{\text {st }}$ premolar

Table 3: Disturbution of premolars according pathology association

\begin{tabular}{|l|l|l|l|l|l|l|}
\hline & \multicolumn{2}{|l|}{ Upper } & \multicolumn{2}{l|}{ Lower } & Total & \\
\cline { 2 - 7 } & $\begin{array}{c}\mathbf{1}^{\text {st }} \\
\text { premolar }\end{array}$ & $\mathbf{2}^{\text {nd }}$ premolar & $\mathbf{1}^{\text {st }}$ premolar & $\mathbf{2}^{\text {nd }}$ premolar & & U X L \\
\hline $\begin{array}{l}\text { With } \\
\text { pathology }\end{array}$ & $0(0 \%)$ & $1(0.99 \%)$ & $0(0 \%)$ & $2(1.98 \%)$ & $3(2.97 \%)$ & $\begin{array}{l}4 \\
\text { X2= } 18.3 \mathrm{P}=0.000(\mathrm{HS})\end{array}$ \\
\hline $\begin{array}{l}\text { Without } \\
\text { pathology }\end{array}$ & $3(2.97 \%)$ & $5(4.95 \%)$ & $12(11.88 \%)$ & $78(77.22 \%)$ & $98(97.02 \%)$ & $\begin{array}{l}5 \\
\mathrm{X} 2=3.33 \mathrm{P}=0.07(\mathrm{NS})\end{array}$ \\
\hline Total & $3(2.97 \%)$ & $6(5.94 \%)$ & $12(11.88 \%)$ & $80(79.20 \%)$ & $101(100 \%)$ & \\
\hline $4 \times 5$ & $\mathrm{X} 2=0.56, \mathrm{P}=0.45(\mathrm{NS})$ & $\mathrm{X} 2=0.31 \mathrm{P}=0.58(\mathrm{NS})$ & & \\
\hline
\end{tabular}

Table 3 clear the relation of pathologic conditions with impacted premolars, the result was 2 lower $2^{\text {nd }}$ premolar and 1 upper $2^{\text {nd }}$ premolar involved with pathology from all sample 
Table 4: No. Of premolar according location (migrated or not)

\begin{tabular}{|l|l|l|l|l|l|l|}
\hline & \multicolumn{2}{|l|}{ Upper } & \multicolumn{2}{l|}{ Lower } & Total & \\
\hline & $\mathbf{1}^{\text {st }}$ & $\mathbf{2}^{\text {nd }}$ & $\mathbf{1}^{\text {st }}$ & $\mathbf{2}^{\text {nd }}$ & & U X L \\
\hline Migrated & $0(0 \%)$ & $0(0 \%)$ & $0(0 \%)$ & $1(0.99 \%)$ & $1(0.99 \%)$ & $\begin{array}{l}4 \\
\mathrm{X} 2=18.3 \mathrm{P}=0.000(\mathrm{HS})\end{array}$ \\
\hline $\begin{array}{l}\text { Not } \\
\text { migrated }\end{array}$ & $3(2.97 \%)$ & $6(5.94 \%)$ & $12(11.88 \%)$ & $79(78.21 \%)$ & $100(99 \%)$ & $\begin{array}{l}5 \\
\mathrm{X} 2=0.08 \mathrm{P}=0.78 \text { (NS) }\end{array}$ \\
\hline Total & $3(2.97 \%)$ & $6(5.94 \%)$ & $12(11.88 \%)$ & $80(79.20 \%)$ & & \\
\hline $4 \times 5$ & $\mathrm{X} 2=6.5, \mathrm{P}=0.09(\mathrm{NS})$ & $\mathrm{X} 2=0.15 \mathrm{P}=0.69(\mathrm{NS})$ & & \\
\hline
\end{tabular}

Table 4 show the ratio of migrated impacted premolars , only one impacted premolar (lower $2^{\text {nd }}$ premolar was migrate from erupted position)

\section{Discussion}

Many local or systemic factors associated with impacted teeth, the most common causes of impacted teeth were local factors which include prolonged retention, ankylosis, early exfoliation of the deciduous tooth, insufficient area, jaw cyst or odontoma.

According to the side involvement with impacted premolars whether unilateral or bilateral indicate the majority of unilateral impacted premolar and this com in agree with ${ }^{(15)}$, our result was as fallow, for bilateral impacted premolars the percentage was $2(2.08 \%)$ from99 patient, for maxillary $1^{\text {st }}$ premolar was $1(1.04)$ and 1 for mandibular $2^{\text {nd }}$ premolar, while for unilateral impacted premolars was $97(97.97 \%)$ which come different from previous study may be due to genetic causes.

Among this study, impaction of premolars was associated with retained primary molars or insufficient area of eruption of all cases. The prevalence of impacted premolars has been reported as fallow: for maxillary premolars was $(8.91 \%)$, while for mandibular premolars was $(91.08 \%)$. In our population, the prevalence of impacted maxillary first and second premolars was $(2.97 \%)$ and $(5.94 \%$, ) respectively, and the prevalence of impacted mandibular first and second premolars was $(11.88 \%)$ and $(79.20 \%)$, respectively. Differences in prevalence rates between this study and previous studies may be due to differences in the genetic causes of the

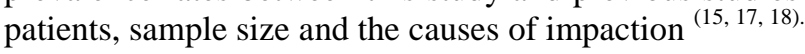

Regarding to the association of impacted premolar with pathologic condition only $1(0.99 \%)$ IP for maxillary $2^{\text {nd }}$ premolar and $2(1.98 \%)$ IP for mandibular $2^{\text {nd }}$ premolar from 101 IP associated with pathologic condition and the remain all free from any pathology and this result refer to a rare condition of pathological association and this result come in agree with ${ }^{(15)}$.

Among 101 impacted premolar it was found $1(0.99 \%) 2^{\text {nd }}$ mand. Premolar migrated away from its path of eruption which direct horizontally and all remaining IP were non migrated and this result confirmwith many

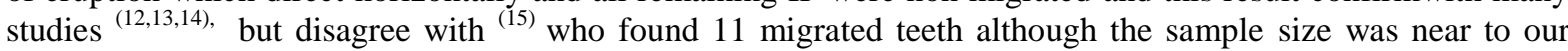
sample size, but in his study all cases were loss $1^{\text {st }}$ permanent molar while our case not , so the disagree return to different causes of impaction, also our study disagree with ${ }^{(16)}$ who said migration undergone over 20 year while in our study the migration tooth was found in patient with age 18 year and this disagreement may return to different race.

\section{Conclusion}

From our study it was found that the most prominent impacted tooth among the premolars it was mand. 2nd premolar followed with and the max. $1^{\text {st }}$ premolar is the less common, unilateral impacted premolar was clear highest than the bilateral which was rare. Impacted premolar percentage in female was higher than the male.

\section{References}

[1]. B. J. Moxham and B. K. Berkovitz, "Interactions between thyroxine, hydrocortisone and cyclophosphamide in their effects on the eruption of the rat mandibular incisor," Archives of Oral Biology, vol. 28, no. 12, 1083-1087, 1983.

[2]. J. O. Andreasen, "The impacted premolar," in Textbook and Color Atlas of Tooth Impactions: Diagnosis Treatment and Prevention, J. O. Andreasen, J. K. Petersen, and D. M. Laskin, Eds., pp. 177-195,Munksgaard, Copenhagen, Denmark, 1997.

[3]. V. J. Oikarinen and M. Julku, "Impacted premolars. An analysis of 10,000 orthopantomograms," Proceedings of the Finnish Dental Society, 1974; 70 (3): 95-98,. 
[4]. Thilander B, Myrberg N: The prevalence of malocclusion in Swedish schoolchildren. Scandinavian Journal of Dental Research, 1973; 81(1):12-21.

[5]. Sutton PR: Migrating nonerupted mandibular premolars:a case of migration into the coronoid process. Journal of Oral Surgery, Oral Medicine and Oral Pathology, 1968; 25(1):87-98.

[6]. Winter GB, Gelbier MJ, Goodman JR: Severe infraocclusion and failed eruption of deciduous molars associated with eruptive and developmental disturbances in the permanent dentition: a report of 28 selected cases. British Journal of Orthodontics, 1997;24(2):149-157.

[7]. 7. Rubin DM, Vedrenne D, Portnof JE. Orthodontically guided eruption of mandibular second premolar following enucleation of an inflammatory cyst: case report. The Journal of Clinical Pediatric Dentistry, 2002; 27(1):19-23.

[8]. 8. Mahajan S, Raj V, Boaz K, George T: Non-syndromic bilateral dentigerous cysts of mandibular premolars: a rare case and review of literature. Hong Kong Dental Journal, 2006; 3(2):129-133.

[9]. 9. Yawaka Y, Kaga M, Osanai M, Fukui A, Oguchi H: Delayed eruption of premolars with periodontitis of primary predecessors and a cystic lesion: a case report. International Journal of Pediatric Dentistry, 2002; 12(1):53-60.

[10]. 10. McNamara C, McNamara TG. Mandibular premolar impaction: 2 case reports. J Can Dent Assoc. 2005;71:859-63.

[11]. 11. J. O. Andreasen, "The impacted premolar," in Textbook andColor Atlas of Tooth Impactions: Diagnosis Treatment and Prevention, J. O. Andreasen, J. K. Petersen, and D. M. Laskin, Eds., pp. 177-195,Munksgaard, Copenhagen, Denmark, 1997

[12]. 12. Shapira Y, Kuftinec MM. Intrabony migration of impacted teeth. Angle Orthod. 2003;73:738-43.

[13]. 13. Infante-Cossio P, Hernandez-Guisado JM, Gutierrez-Perez JL. Removal of a premolar with extreme distal migration by sagittal osteotomy of the mandibular ramus: report of case. J Oral Maxillofac Surg. 2000;58:575-7.

[14]. 14. Matteson SR, Kantor ML, Proffit WR. Extreme distal migration of the mandibular second bicuspid. A variant of eruption. Angle Orthod. 1982;52:11-8.

[15]. 15. Şimşek-Kaya G, Melih-Ömezli M, Yapici G, Dayi E, Ertaş U. Prevalence of impacted premolars in a Turkish population and considerations for surgical treatment. Med Oral Patol Oral Cir Bucal. 2011 Sep 1;16 (6):e781-6.

[16]. 16. Sutton PR. Migrating nonerupted mandibular premolars: a case of migration into the coronoid process. Oral Surg Oral Med Oral Pathol. 1968;25:87-98.

[17]. 17. Chu FC, Li TK, Lui VK, Newsome PR, Chow RL, Cheung LK. Prevalence of impacted teeth and associated pathologies--a radiographic study of the Hong Kong Chinese population. Hong Kong Med J. 2003;9:158-63.

[18]. 18.Lee PP. Impacted premolars. Dent Update. 2005;32:152-4,157.

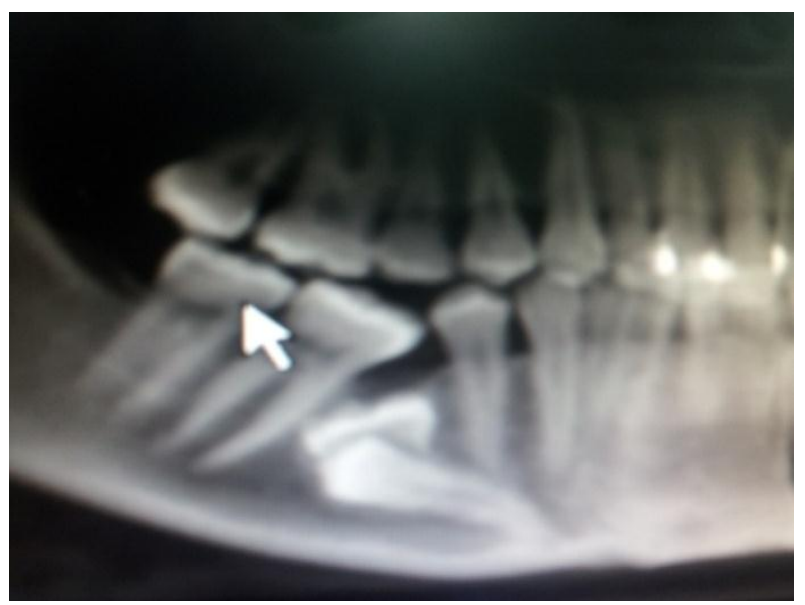

Figure 1: show impacted mand 2nd premolar with impacted E

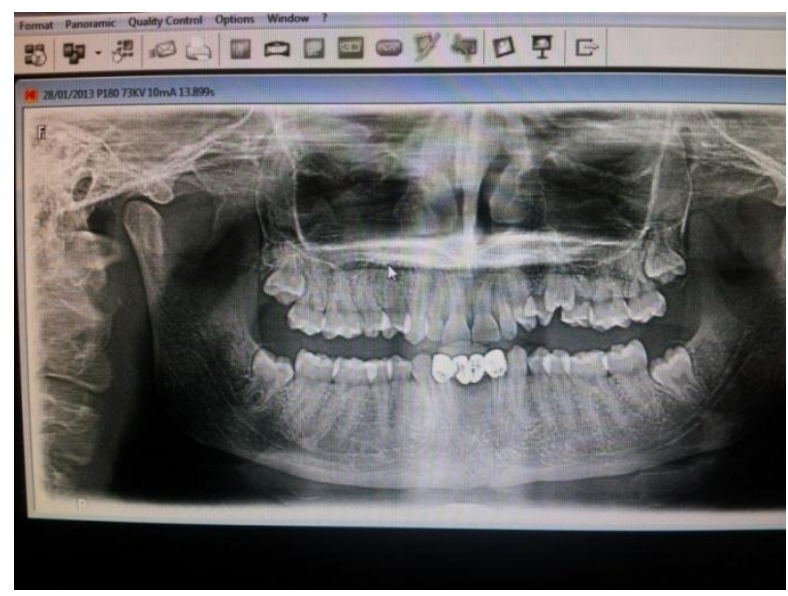

Figure 2: show impacted max.2nd premolar Lt. side 


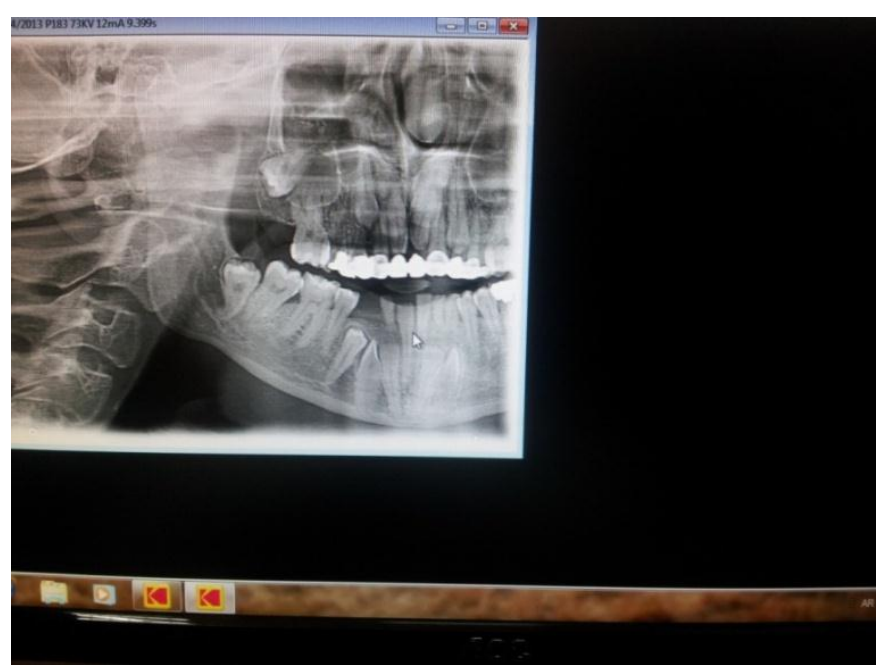

Figure 3: show patient with multiple impacted teeth although patient age was 19 year and Rt. mand $2^{\text {nd }}$ premolar 